\title{
Cushing's disease: Does low-dose pasireotide offer a comparable efficacy and safety to high-dose?
}

\author{
Mimi Wong1,2, Usman H Malabu1,3, Ipeson Korah4 and YongMong Tan ${ }^{1,3}$ \\ 1Department of Diabetes and Endocrinology, Townsville University Hospital, Queensland, Australia, 2School of \\ Medicine, University of Queensland, Queensland, Australia, ${ }^{3}$ College of Dentistry and Medicine, James Cook \\ University, Queensland, Australia, and 4Department of Radiology, Townsville University Hospital, \\ Queensland, Australia
}

\author{
Correspondence \\ should be addressed \\ to M Wong \\ Email \\ mimi.wong@uqconnect. \\ edu.au
}

\section{Summary}

Whilst literature is expanding on pasireotide use in the management of Cushing's disease (CD), there is still currently much unknown about long-term and low-dose pasireotide use in CD. We present a 60-year-old female with residual CD after transphenoidal surgery (TSS), being successfully managed with S.C. pasireotide for over 10 years. For 6 years, her S.C. pasireotide was inadvertently administered at $360 \mu \mathrm{g}$ twice daily (BID), almost half the recommended dose of $600 \mu \mathrm{g}$ BID. Despite the low-dose, her urinary free cortisol (UFC) normalised within 6 months and Cushingoid features resolved. She remained in biochemical and clinical remission on the same low-dose for 6 years, before a medication audit discovered her mistaken dose and directed her to take $600 \mu \mathrm{g}$ BID. With the higher dose $600 \mu \mathrm{g}$ BID for the next 5 years, her glycaemia worsened without any changes in her UFC and residual tumour volume. Our case showed the continuing effectiveness and safety of treatment with S.C. pasireotide for more than 10 years, and that a low-dose regimen may be considered an option for responders by its safety profile.

\section{Learning points:}

- A lower dose of pasireotide may be effective in the initial treatment of $C D$ than the recommended $600 \mu g$ BID dosage, though more studies are required to explore this.

- Low-dose pasireotide use has the benefit of minimising adverse effects.

- In the long-term, pasireotide has a sustained clinical and biochemical effect and is well tolerated.

\section{Background}

Cushing's disease $(\mathrm{CD})$ is rare and relates to excess corticotropin secretion from a pituitary adenoma. Early diagnosis and treatment are important, as the duration of exposure to excess glucocorticoids is predictive of mortality (1). First-line treatment is transphenoidal surgery (TSS), with medical therapies suggested in those who are not surgical candidates or have persistent or recurrent $\mathrm{CD}(2)$.

Corticotroph adenomas express somatostatin (SSTR) and dopamine receptors, and both can be therapeutic targets. Pasireotide, a somatostatin analogue which binds to four of the five SSTR, with the highest affinity to SSTR5 , can be used in $\mathrm{CD}$. It can cause rapid reductions in UFC and improve Cushingoid features, quality of life and pituitary tumour volume (2).

The US Endocrine Society Clinical Guidelines recommends commencing S.C. pasireotide at $600 \mu \mathrm{g}$ BID in CD (2). Currently, there is limited literature on the effectiveness and long-term safety of using a lower dose of pasireotide. Here we present a patient who was 
treated with S.C. pasireotide for over 10 years, of which 6 years were with a lower than conventionally recommended dose.

\section{Case presentation}

A 60-year-old female was diagnosed with CD in June 2009. Ten years before she had a coronary artery bypass graft for ischaemic heart disease. There was no prior history of diabetes mellitus or hypertension. She had presented with a two-month history of fluid retention, increased perioral hair, easy bruising, weight gain, proximal muscle weakness, polydipsia and nocturia. There was no history of exogenous glucocorticoid use. She was hypertensive with blood pressure (BP) of 150/100 $\mathrm{mmHg}$ and showed Cushingoid features of rounded facies, abdominal bruising and peripheral oedema. There was no visual field defect or cranial nerve palsies.

\section{Investigations}

Initial biochemistry (Table 1) showed hypernatraemia, hypokalaemia, metabolic alkalosis and hyperglycaemia. Initial screening through two 24-h UFC and low dose dexamethasone suppression test confirmed hypercortisolism. Midnight salivary cortisol as a screening test was not adequately established at the time and was not pursued. The interpretation of her biochemistry was

Table 1 Initial diagnostic evaluation of Cushing's disease.

\begin{tabular}{|c|c|c|}
\hline & Result & Reference range \\
\hline \multicolumn{3}{|l|}{ Electrolytes } \\
\hline Sodium, mmol/L & 147 & $135-145$ \\
\hline Potassium, $\mathrm{mmol} / \mathrm{L}$ & 2.4 & $3.5-5.0$ \\
\hline Bicarbonate, mmol/L & 42 & $23-32$ \\
\hline Fasting glucose, $\mathrm{mmol} / \mathrm{L}$ & 8.6 & \\
\hline \multicolumn{3}{|l|}{ Baseline (morning) } \\
\hline Serum cortisol, nmol/L & 1325 & \\
\hline ACTH, ng/L & 135 & $9-51$ \\
\hline Baseline 24 h UFC & & $25-180$ \\
\hline Sample 1, nmol/day & 1868 & \\
\hline Sample 2, nmol/day & 1051 & \\
\hline \multicolumn{3}{|l|}{ Low dose DST* } \\
\hline Serum cortisol, nmol/L & 563 & $<140^{\dagger}$ \\
\hline UFC, $\mu \mathrm{mol} / \mathrm{day}$ & $936(49.9 \%) *$ & $<50 \% *,+$ \\
\hline \multicolumn{3}{|l|}{ High dose DST\# } \\
\hline Serum cortisol, $\mathrm{nmol} / \mathrm{L}$ & $579(56 \%)$ & $<50 \%$ **; \\
\hline $\mathrm{UFC}, \mu \mathrm{mol} / \mathrm{day}$ & $636(65 \%) *$ & $<50 \%$ **, \\
\hline
\end{tabular}

*Dexamethasone $0.5 \mathrm{mg}$ every 6-hourly over 48 h; \#Dexamethasone $2 \mathrm{mg}$ every 6-hourly over $48 \mathrm{~h}$; ${ }^{\dagger}$ Normal response; * *percent suppression from baseline; ${ }^{\ddagger}$ Response in Cushing's disease.

ACTH, adrenocorticotropic hormone; DST, dexamethasone suppression test; UFC, urinary free cortisol. in relation to reference ranges of local laboratories and work-up was guided by the Endocrine Society guidelines. It is acknowledged that a dexamethasone-corticotropinreleasing hormone $(\mathrm{CRH})$ test is recommended to diagnose CD (1), however, at the time, CRH was not readily available in Australia. CD was diagnosed following high dose dexamethasone suppression test and MRI which revealed a right-sided pituitary macroadenoma measuring $10.6 \times 12.7 \times 14.9 \mathrm{~mm}$ height, transverse and anteroposterior dimensions respectively with pituitary stalk deviation to the left and encompassment of the right internal carotid artery (Fig. 1A).

Her pre-surgery serum follicle-stimulating hormone (FSH) and luteinising hormone (LH) were suppressed perhaps due to hormonal and mechanical effects of the macroadenoma but subsequently returned to the postmenopausal levels after surgery and while on treatment with pasireotide. Her insulin-like growth factor 1, thyroid function tests and prolactin were normal (Table 2).

\section{Treatment}

Pre-operatively her diabetes was managed with metformin 2 g daily and insulin (NovoMix30 (30\% aspart and 70\% protamine) 20 units morning and 14 units evening). Her HbA1c was $7.8 \%$ in June 2009, and was not repeated prior to TSS as it was to be pursued in 2 months. On this regimen her blood glucose levels ranged between 9 and $13 \mathrm{mmol} / \mathrm{L}$.

Transphenoidal debulking surgery was undertaken in August 2009, however, as the pituitary macroadenoma was in close proximity to the internal carotid artery, complete resection was not possible. Pituitary MRI 2 months post-TSS showed a residual right-sided nonenhancing heterogeneous mass of $6.6 \times 5.5 \times 8.5$ $\mathrm{mm}$, though its exact measurement is confounded by post-operative changes (Fig. 1B). Histopathological examination showed infiltration of eosinophilic cell and immunohistochemistry revealed the presence of adrenocorticotropic hormone (ACTH) staining on her pituitary adenoma, confirming the diagnosis of Cushing's disease.

\section{Outcome and follow-up}

Post-operatively she had ongoing Cushingoid features, with BP of 140/90 mmHg and was still biochemically hypercortisolemic though it had improved (Fig. 2). Fourteen days post-operatively her UFC was $1430 \mathrm{nmol} /$ day (80-590), morning serum cortisol $610 \mathrm{nmol} / \mathrm{L}$ 


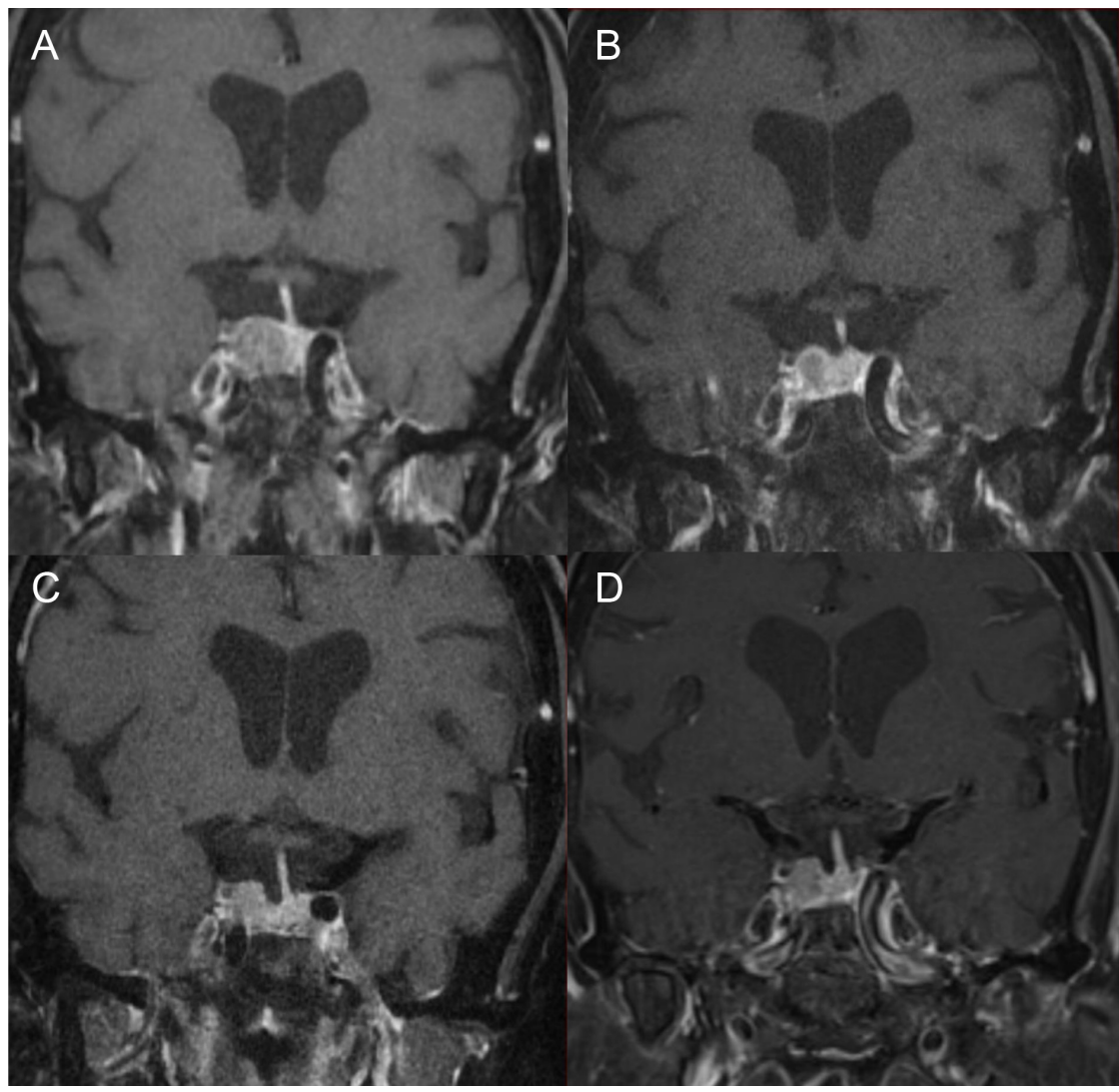

\section{Figure 1}

Coronal non-contrast MRI pituitary view of pituitary macroadenoma over course of treatment. (A) Pre-transphenoidal surgery. (B) 2 months post-transphenoidal surgery. (C) Six years on subcutaneous pasireotide $360 \mu \mathrm{g}$ twice daily. (D) Five years with the higher dose of subcutaneous pasireotide $600 \mu \mathrm{g}$ twice daily (11 years of pasireotide treatment in total).

(220-720) and ACTH $51 \mathrm{ng} / \mathrm{L}$ (5-50). Though there is no consensus, the US Endocrine Society Clinical Guidelines recommends for ACTH-producing tumours remission can be defined if 7 days post-operatively serum cortisol levels are less than $138 \mathrm{nmol} / \mathrm{L}$ or UFC are less than $28-56 \mathrm{nmol} /$ day (2). Based on this and her ongoing clinical features and MRI post-operatively, our patient had residual CD post-TSS.

Radiosurgery was largely precluded by the distance of travel for our patient. In September 2009. she was commenced on S.C. pasireotide, inadvertently self-

Table 2 Pituitary profile at diagnosis of Cushing's disease.

\begin{tabular}{|c|c|c|}
\hline Test & Result & Reference range \\
\hline Morning serum cortisol, nmol/L & 1325 & \\
\hline $\mathrm{ACTH}, \mathrm{ng} / \mathrm{L}$ & 135 & $9-51$ \\
\hline Free T4, pmol/L & 9.8 & $9-19$ \\
\hline $\mathrm{TSH}, \mathrm{mIU} / \mathrm{L}$ & 1.3 & $0.3-5.0$ \\
\hline FSH, IU/L & $<2$ & $20-140$ \\
\hline $\mathrm{LH}, \mathrm{IU} / \mathrm{L}$ & $<1$ & $10-65$ \\
\hline Oestradiol, pmol/L & 70 & $40-200$ \\
\hline IGF-1, nmol/L & 15 & $9-38$ \\
\hline Prolactin, mIU/L & 333 & $<500$ \\
\hline
\end{tabular}

ACTH, adrenocorticotropic hormone; FSH, follicle-stimulating hormone; IGF-1, insulin-like growth factor 1; LH, luteinising hormone; $\mathrm{TSH}$, thyroid-stimulating hormone. administered as $360 \mu \mathrm{g}$ BID. Instead of administering the full $1 \mathrm{~mL}$ vial of $600 \mu \mathrm{g}$ pasireotide, our patient mistakenly administered $0.6 \mathrm{~mL}$ which she thought correlated with $0.6 \mathrm{mg}$ pasireotide. To accurately measure $0.6 \mathrm{~mL}$ she used a $1 \mathrm{~mL}$ syringe to draw up pasireotide from the vial. Within 6 months of pasireotide treatment, her UFC had normalised (160 nmol/day), and within a year she was clinically in remission. She became normotensive with BP of 100/80 $\mathrm{mmHg}$, her Cushingoid features resolved and diabetes was managed with metformin alone. Following 12 months of pasireotide treatment, she remained in biochemical remission with UFC $130 \mathrm{nmol} /$ day, morning serum cortisol $340 \mathrm{nmol} / \mathrm{L}$ and ACTH $12 \mathrm{ng} / \mathrm{L}$.

She continued with S.C. pasireotide $360 \mu \mathrm{g}$ BID from September 2009 to June 2015 when a medication audit discovered the mistaken lower dose. This administration error was not detected earlier as she was responding well with pasireotide, and hence her medical schedule was not checked. Furthermore, as she lived in a rural area and a distance from her endocrinologist, this likely contributed to this error not been detected earlier. Following this finding her S.C. pasireotide dose was corrected to $600 \mu \mathrm{g}$ BID despite her clinical and biochemical remission on the lower dose (Fig. 2). Her dosage was increased in order for her to continue her compassionate supply of pasireotide. 


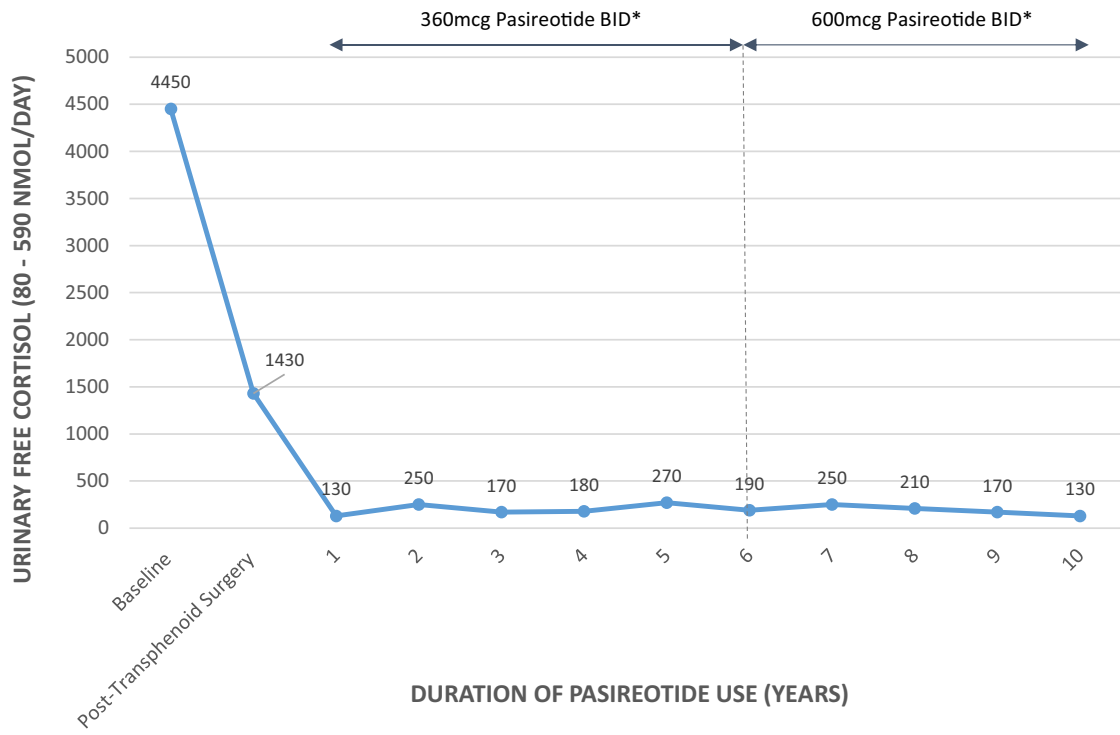

\section{Figure 2}

Twenty-four hours urinary free cortisol measurements in relation to duration and dosage of pasireotide. *BID, twice daily.
While on the lower pasireotide dose her diabetes was well controlled on metformin $2 \mathrm{~g}$ daily and with the subsequent addition of gliclazide modified release (MR) $30 \mathrm{mg}$ daily (Fig. 3). Her HbA1c was $6.8 \%$ after 1 year on low-dose pasireotide and 7.0\% in May 2015, just prior to cessation of low-dose pasireotide. Progress pituitary MRI following 6 years on low-dose S.C. pasireotide did not show any residual tumour reduction with it measuring $8.2 \times 6.6 \times 12 \mathrm{~mm}$ (Fig. 1C).

From June 2015 she started S.C. pasireotide 600 ug BID. She has been on this higher dose for 5 years and remains in clinical and biochemical remission

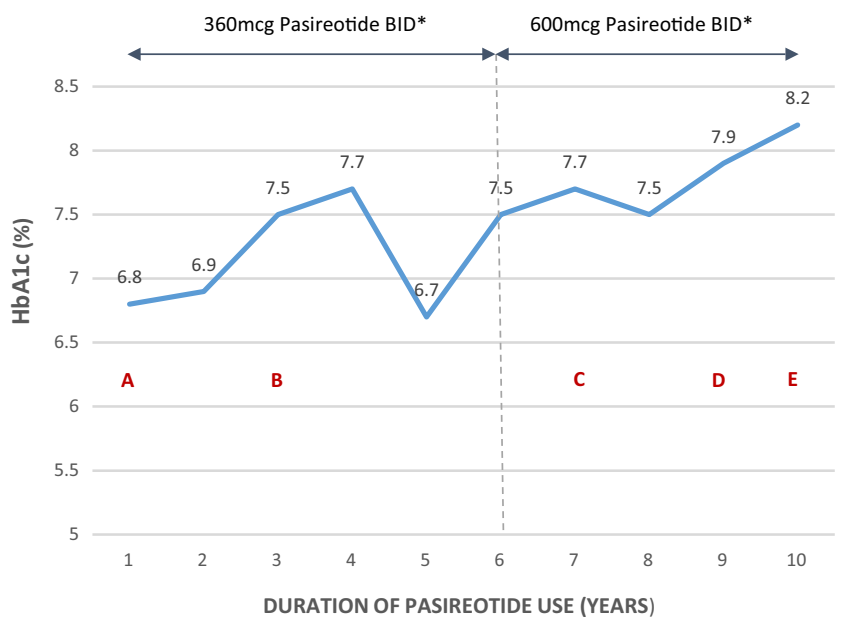

\section{Figure 3}

$\mathrm{HbA1C}(\%)$ in relation to duration and dosage of pasireotide, and glycaemic management. *BID, twice daily. (A, B, C, D and E) shows escalating anti-diabetes medications with (A) (metformin), (B) (+ gliclazide modified release), (C) (+ empagliflozin), (D) (+ sitagliptin) and (E) (+glargine insulin).
(Fig. 2), with her UFC being $130 \mathrm{nmol} /$ day, serum cortisol $570 \mathrm{nmol} / \mathrm{L}$ and ACTH $6.3 \mathrm{pmol} / \mathrm{L}(1.1-11.1)$ at 5 years following high-dose pasireotide use. Despite the increased pasireotide dose and addition of cabergoline $0.5 \mathrm{mg}$ twice weekly from December 2014, which was added with the goal of reducing her pituitary mass, there has not been any change in her pituitary tumour on MRI with it measuring $8.1 \times 6.9 \times 12.8 \mathrm{~mm}$ following 5 years of high-dose pasireotide (Fig. 1D). The increased pasireotide dose, however, worsened her glycaemic control (Fig. 3) with $\mathrm{HbA1c}$ rising to $7.5 \%$ within 3 months. Despite increasing her gliclazide MR to $120 \mathrm{mg}$ and adding empagliflozin $10 \mathrm{mg}$ daily and sitagliptin $100 \mathrm{mg}$ daily to her metformin, her HbA1c progressively rose to $8.2 \%$ after 5 years of high-dose pasireotide. She has now commenced glargine insulin.

Her pituitary axes continued to be monitored postTSS and whilst on pasireotide. LH and FSH in 2010 rose to post-menopausal levels of 55 and $90 \mathrm{IU} / \mathrm{L}$, respectively, with oestradiol of $140 \mathrm{pmol} / \mathrm{L}(<120)$. Thyroid function remained normal to her last follow-up with thyroid-stimulating hormone of $3.1 \mathrm{mIU} / \mathrm{L}$ (0.54.0) in October 2020. Prolactin levels were low and suppressed from the addition of cabergoline to her treatment in October 2020. With her post-menopausal status and hypercortisolism, bone mineral density (BMD) was monitored. BMD by Norland DEXA in 2011 showed her lumbar spine $\mathrm{T}$ score -2.1 and femoral neck -2.0. A progress BMD by Norland in 2014 showed improvement in her lumbar spine $\mathrm{T}$ score to -1.7 and femoral neck unchanged at -2.0 , most likely the result of normalisation of hypercortisolism. 


\section{Discussion}

Here we present a case of long-term low-dose pasireotide use to treat residual CD. UFC normalised within 6 months and clinical remission was achieved within 1 year.

Our patient was managed with low-dose pasireotide for 6 years, and remained in clinical and biochemical remission throughout the period. She subsequently received S.C. pasireotide $600 \mu \mathrm{g}$ BID, which continued to keep her in clinical and biochemical remission for another 5 years. The higher pasireotide dose, however, worsened her glycaemic control with her HbA1c increasing from 7.0 to $8.2 \%$ with escalating anti-diabetic medications. In total, our patient has been on S.C. pasireotide for 11 years. Apart from worsened glycaemic control, she has not developed other complications such as cholelithiasis, liver dysfunction or hypothyroidism. Her ischaemic heart disease remains stable.

The initial pasireotide dosage of $360 \mu \mathrm{g}$ BID used to secure and maintain remission in our patient appears to be lower than those described in the literature and suggests the suitability of lower dose S.C. pasireotide for responders. Feelders et al used low-dose pasireotide $250 \mu \mathrm{g}$ SC three times daily for 28 days in 17 patients with CD and achieved normalisation of UFC in $29 \%$ (3). There are also case reports of low-dose S.C. pasireotide $300 \mu \mathrm{g}$ BID being used in CD, though they follow initial treatment with 600-1200 $\mu \mathrm{g}$ BID $(4,5)$. We report a novel finding of initial low-dose pasireotide use in $\mathrm{CD}$, though more studies exploring predictive factors to guide low-dose pasireotide use are needed. Currently, there is no identifiable factor to predict the temporal development of adrenal insufficiency for patients on pasireotide, and severity of hypercortisolism and response to pasireotide is unclear. The acute pasireotide suppression test may assist with predicting response to pasireotide, and the development of a similar test to guide the initial use of low-dose pasireotide may be helpful in the future (6).

Tumour shrinkage appears to be dose-dependent though in our patient both the low and high doses of pasireotide did not reduce residual pituitary tumour. Colao et al. reported following 12 months of pasireotide, a mean change in pituitary tumour volume of $-9.1 \%$ with $600 \mu \mathrm{g}$ BID, and $-43.8 \%$ with $900 \mu \mathrm{g}$ BID (7). Interestingly Grossrubatscher et al. treated their patient with S.C. pasireotide $600 \mu \mathrm{g}$ BID for one month and then with a lower dose of $300 \mu \mathrm{g}$ BID, and reported that a shrinkage of $-44 \%$ at 6 months and $-52 \%$ at 18 months was achieved. The mechanism of tumour shrinkage by pasireotide is unclear though it may have antiproliferative effects on corticotroph adenomas (5).

Low-dose pasireotide may have the advantage of minimising adverse effects (5). Our patient had good glycaemic control on $360 \mu \mathrm{g}$ BID with her HbA1c had been $7.0 \%$ after 6 years of pasireotide whilst on metformin $2 \mathrm{~g}$ and gliclazide MR $30 \mathrm{mg}$. Her glycaemic control worsened with the $600 \mu \mathrm{g}$ BID dose with her HbA1c rising to 8.2\% after 5 years despite increasing her gliclazide MR and adding empagliflozin and sitagliptin. Increased rates of hyperglycaemia have been observed with higher doses (7), and dose increments (4) of pasireotide.

It is unlikely that her underlying $\mathrm{CD}$ contributed to worsening glycaemia as she was in remission. The worsened glycaemia occurred 3 months after increased dosage of pasireotide with her HbA1c rising from 7.0 to 7.5\%. Pasireotide can bind to SSTR on pancreatic islet cells and $\mathrm{K}$ and $\mathrm{L}$ cells, reducing insulin, glucagon-like peptide- 1 and glucose-independent insulinotropic polypeptide levels, and subsequently, lead to hyperglycaemia (8). Although there are no guidelines for pasireotideassociated hyperglycaemia, expert recommendations are for initial lifestyle measures and metformin followed by incretin-based therapies given the associated pathophysiological mechanism. DDP4-inhibitors can be second-line therapies, followed by GLP-1 receptor agonists (9). Following metformin, gliclazide MR was used in our patient as it was previously a standard anti-diabetes medications and its commencement preceded expert recommendations and the mechanistic model describing pasireotide and its effect on glycaemia $(8,9)$. Though our patient has ischaemic heart disease, the ADVANCE trial where gliclazide MR was the background anti-diabetes medications, showed gliclazide MR had not adversely affected cardiovascular outcome. With our patient also on glargine insulin, Government prescribing subsidy restrictions precluded the use of GLP-1 receptor agonists.

Our patient has sustained benefit for over 10 years and apart from hyperglycaemia, was not associated with other adverse effects. One of the strength of our case report is that our patient has been managed with pasireotide for $\mathrm{CD}$ for the longest duration in Australia and in the current literature. Petersenn et al. reported after 5 years of pasireotide, normalisation of UFC in $11 / 16$ patients, median tumour volume change of $-3.5 \%$, and safety profile at 5 years similar to that at 12 and 24 months (10). Following 5 years of pasireotide use, there is limited literature.

In conclusion, we present a case of residual CD that successfully achieved long-term clinical and biochemical 
remission with low-dose S.C. pasireotide $360 \mu \mathrm{g}$ BID. Our patient illustrates an option for long-term use of a lower dose S.C. pasireotide than the recommended 600 $\mu \mathrm{g}$ BID for responders without significantly worsening their glycaemia. Our patient has been treated with S.C. pasireotide for more than 10 years, with good tolerability and sustained efficacy.

\section{Declaration of interest}

Compassionate supply of pasireotide was initially through Novaratis and subsequently through Recordati.

\section{Funding}

This research did not receive any specific grant from any funding agency in the public, commercial or not-for-profit sector.

\section{Patient consent}

Written informed consent for publication has been obtained from the patient.

\section{Author contribution statement}

Dr Wong was involved with collating clinical data and writing of the manuscript. Prof Malabu was involved with editing. Dr Korah was the radiologist involved. Dr Tan was the treating endocrinologist, and was involved with editing of the manuscript.

\section{References}

1 Nieman LK, Biller BMK, Findling JW, Newwll-Price J, Savage MO, Stewart PM \& Montori VM. The diagnosis of Cushing's syndrome: an Endocrine Society clinical practice guideline. Journal of Clinical Endocrinology and Metabolism 200893 1526-1540. (https://doi. org/10.1210/jc.2008-0125)
2 Nieman LK, Biller BMK, Findling JW, Murad MH, Newell-Price J, Savage MO, Tabarin A \& Endocrine Society. Treatment of Cushing's syndrome: an endocrine society clinical practice guideline. Journal of Clinical Endocrinology and Metabolism 2015100 2807-2831. (https:// doi.org/10.1210/jc.2015-1818)

3 Feelders RA, de Bruin C, Pereira AM, Romijn JA, Netea-Maier RT, Hermus AR, Zelissen PM, van Heerebeek R, de Jong FH, van der Lely AJ, et al. Pasireotide alone or with cabergoline and ketoconazole in Cushing's disease. New England Journal of Medicine 2010362 1846-1848. (https://doi.org/10.1056/NEJMc1000094)

4 Trementino L, Cardinaletti M, Concettoni C, Marcelli G, Boscaro M \& Arnaldi G. Up-to 5-year efficacy of pasireotide in a patient with Cushing's disease and pre-existing diabetes: literature review and clinical practice considerations. Pituitary 201518 359-365. (https:// doi.org/10.1007/s11102-014-0582-9)

5 Grossrubatscher E, Zampetti B, Dalino Ciaramella P, Doneda P \& Loli P. Effectiveness of low-dose pasireotide in a patient with Cushing's disease: antiproliferative effect and predictivity of a short pasireotide suppression test. Clinical Case Reports 20153 718-722. (https://doi.org/10.1002/ccr3.321)

6 Trementino L, Zilio M, Marcelli G, Michetti G, Barbot M, Ceccato F, Boscaro M, Scaroni C \& Arnaldi G. The role of an acute pasireotide suppresion test in predciting response to treatment in patients with Cushing's disease: findings from a pilot study. Endocrine $2015 \mathbf{5 0}$ 154-161. (https://doi.org/10.1007/s12020-014-0499-0)

7 Colao A, Petersenn S, Newell-Price J, Findling JW, Gu F, Maldonado M, Schoenherr U, Mills D, Salgado LR, Biller BMK, et al. A 12-month phase 3 study of pasireotide in Cushing's disease. New England Journal of Medicine 2012366 914-924. (https://doi. org/10.1056/NEJMoa1105743)

8 Henry RR, Ciaraldi TP, Armstrong D, Burke P, Ligueros-Saylan M \& Mudaliar S. Hyperglycemia associated with pasireotide: results from a mechanistic study in healthy volunteers. Journal of Clinical Endocrinology and Metabolism 201398 3446-3453. (https://doi. org/10.1210/jc.2013-1771)

9 Colao A, De Block C, Gaztambide MS, Kumar S, Seufert J \& Casanueva FF. Managing hyperglycemia in patients with Cushing's disease treated with pasireotide: medical expert recommendations. Pituitary 201417 180-186. (https://doi.org/10.1007/s11102-0130483-3)

10 Petersenn S, Salgado LR, Schopohl J, Portocarrero-Ortiz L, Arnaldi G, Lacroix A, Scaroni C, Ravichandran S, Kandra A \& Biller BMK. Longterm treatment of Cushing's disease with pasireotide: 5-year results from an open-label extension study of a phase III trial. Endocrine 201757 156-165. (https://doi.org/10.1007/s12020-017-1316-3)

Received in final form 20 January 2021

Accepted 2 February 2021 